\title{
Complementation and Recombination Studies on Cell Fusion by Herpes Simplex Virus Type 2 Utilizing Non-fusing Mutants
}

\author{
SHIGERU YAMAMOTO, HIDEFUMI KABUTA AND KANJI IKEUCHI \\ Department of Virology, Kurume University School of Medicine, \\ Kurume, 830 Japan
}

Received for publication November 29, 1982

\begin{abstract}
Summary: Eight $\mathrm{r}$ mutants, which are defective in fusion function, were isolated following BUDR mutagenesis of a syncytial strain of herpes simplex virus type 2 (HSV 2). Most of the mutant pairs complemented each other and resulted in cell fusion, thus the $\mathrm{r}$ mutants could be classified into seven complementation groups. $\mathrm{R}$ mutants belonging to different complementation groups recombined effectively with each other, making it possible to construct a linkage map based on fusion function.
\end{abstract} map

Key words: HSV2 - cell fusion - complementation - recombination - linkage

\section{Introduction}

Our previous studies (Yamamoto and Kabuta, 1977) on genetic analysis have demonstrated that six cistrons are associated with the cell fusion function of herpes simplex virus type 1 (HSV1). The use of $\mathrm{r}$ mutants, non-fusing mutants isolated following mutagenesis of syncytium forming virus with BUDR, has revealed that the mutants can be classified into four complementation groups and mapped by recombination experiments. From a structural and functional viewpoint of genomes of both types of $\mathrm{HSV}$, it is interesting to determine whether the cistrons of HSV1 are functionally equivalent to those of HSV2.

The present report describes the isolation of mutants, the complementation, recombination, and construction of a linkage map based on the fusion function of HSV2.

\section{Materials and Methods}

Cells and viruses

Cells cloned from GMK cells (a continuous cell line derived from the African green monkey kidney) were used throughout the present experiments. The cells were propagated as previously described (Yamamoto and Kabuta, 1977). The NG strain isolated from a penile lesion (Suenaga, 1972) was used as an original virus strain of HSV2. The isolation of non-fusing mutants (designated $\mathrm{r}$ mutants) is described in the text. The virus assay was carried out by the plaque technique described previously (Yamamoto and Kabuta, 1977).

\section{Complementation}

The complementation test was carried out by simultaneous infection of GMK cell monolayers with two different $r$ mutants. An extensive cell fusion (syncytium formation) in the doubly infected cell monolayers was assumed to be the consequence 
of complementation between the two $r$ mutants in the cells.

Monolayers of approxinately $2 \times 10^{6} \mathrm{GMK}$ cells in bottles were doubly infected with $\mathrm{r}$ mutants at multiplicities of infection $(\mathrm{m}$. o. i.) of 2.5 plaque forming units (PFU)/ cell per virus or singly infected with each virus at an m. o. i. of $5 \mathrm{PFU} /$ cell. After adsorption for 1.5 hours at $37{ }^{\circ} \mathrm{C}$, the cultures were washed twice with $5 \mathrm{ml}$ MEM and maintained in $4 \mathrm{ml}$ MEM. After 20 hours of incubation at $37^{\circ} \mathrm{C}$ the cultures were checked microscopically for cytopathic changes, syncytia formation or cell rounding.

\section{Recombination}

After the bottle cultures were examined for complementation as described above, they were harvested by freezing - thawing and were sonicated for 30 seconds. The progeny viruses obtained were plated on GMK cell monolayers to produce approximately 100 plaques per bottle. The plaques were counted and scored as syncytial or rounding phenotypes. Recombination frequency (RF) was determined by dividing the yield of the syncytial phenotype by the total yield and multiplying by 200 .

\section{Results}

\section{Isolation of mutants}

A virus (designated NG-G211) which expressed a syncytial phenotype and formed plaques larger $(3-4 \mathrm{~mm})$ than the original NG strain (less than $1 \mathrm{~mm}$ ) was obtained through the same processes that have been described for the HSV1 strain YH (Yamamoto et al. 1972). It occurred after at least two steps of spontaneous mutations during serial passages in GMK cells.

The syncytial strain, NG-G211, was used for mutagenesis to isolate $r$ mutants which defect in cell fusion function. GMK cell monolayers were inoculated at a m. o.i. of 0.5 PFU of NG-G211 per cell. After adsorption for 1.5 hours the cultures were washed twice with MEM and grown at 37 ${ }^{\circ} \mathrm{C}$ for 40 hours in MEM with $2.5 \mu \mathrm{g}$ of 5 bromodeoxyuridine per $\mathrm{ml}$. Virus growth in the presence of the drug reduced the virus titer to approximately one sixtieth of the control culture. The mutagenized stock was plated and small plaques containing rounded cells were selected and isolated. The mutants were further purified following three more cycles of plaque isolation.

Eight $r$ mutants, designated $r 301$ to r308, were obtained from 26,873 plaques produced by the mutagenized stock. The $r$ mutants formed plaques of approximately $1 \mathrm{~mm}$ in diameter and induced rounding of cells. The yield of these mutants ranged from 45 (r302) to 180 PFU (r304) per cell, if $4 \times 10^{6} \mathrm{GMK}$ cells were infected with each mutant at a m.o.i. of 2 PFU per cell and harvested after 20 hours incubation at $37^{\circ} \mathrm{C}$.

\section{Complementation}

To determine whether the eight $\mathrm{r}$ mutants were defective at the same loci, complementation tests was performed with mutant pairs. When cells are infected with two mutant viruses that are defective at the same loci, the infected cells will become rounded. If two mutants are defective at different loci, there will be extensive cell fusion or syncytia formation through complementation.

TABLE 1

Complementation between $r$ mutants of type 2 strain $N G$

\begin{tabular}{cccccccc}
\hline & r302 & r303 & r304 & r305 & r306 & r307 & r308 \\
\hline r301 & + & - & + & + & + & + & + \\
r302 & & + & + & + & + & + & + \\
r303 & & & - & + & + & + & + \\
r304 & & & & + & + & + & + \\
r305 & & & & & + & + & + \\
r306 & & & & & & + & + \\
r307 & & & & & & & + \\
\hline
\end{tabular}


TABLE 2

Progeny yields from mixed infections of $r$ mutants

\begin{tabular}{|c|c|c|c|c|c|c|c|c|}
\hline & r301 & r302 & r303 & r304 & r305 & r306 & r307 & r308 \\
\hline & $\left(4.3 \times 10^{6}\right)$ & $\left(2.4 \times 10^{6}\right)$ & $\left(2.1 \times 10^{6}\right)$ & $\left(1.9 \times 10^{7}\right)$ & $\left(5.4 \times 10^{6}\right)$ & $\left(6.2 \times 10^{6}\right)$ & $\left(3.1 \times 10^{6}\right)$ & $\left(3.2 \times 10^{6}\right)$ \\
\hline r301 & & $7.3 \times 10^{6}$ & 3. $7 \times 10^{6}$ & $1.3 \times 10^{7}$ & $1.4 \times 10^{7}$ & $8.8 \times 10^{6}$ & $6.9 \times 10^{6}$ & $6.9 \times 10^{6}$ \\
\hline r302 & & & $8.0 \times 10^{6}$ & $1.5 \times 10^{7}$ & $1.6 \times 10^{7}$ & $8.8 \times 10^{6}$ & $5.8 \times 10^{6}$ & $8.8 \times 10^{6}$ \\
\hline r303 & & & & $1.5 \times 10^{7}$ & $2.3 \times 10^{7}$ & $1.5 \times 10^{7}$ & $9.9 \times 10^{6}$ & $1.3 \times 10^{7}$ \\
\hline r304 & & & & & $2.0 \times 10^{7}$ & $1.6 \times 10^{7}$ & $1.6 \times 10^{7}$ & $2.0 \times 10^{7}$ \\
\hline r305 & & & & & & $1.2 \times 10^{7}$ & $1.2 \times 10^{7}$ & $1.3 \times 10^{7}$ \\
\hline r306 & & & & & & & $1.0 \times 10^{7}$ & $9.2 \times 10^{6}$ \\
\hline r307 & & & & & & & & $7.3 \times 10^{6}$ \\
\hline
\end{tabular}

Yields in the table are indicated as PFU (plaque forming units) per $0.2 \mathrm{ml}$ of cultures. Numbers in parentheses represent the yield from single infections:

As shown in Table 1, 26 of 28 mutant pairs complemented each other. No complementation was observed between r 301 and r303, and between r303 and r304. This suggestts that $\mathrm{r} 303$ possesses a double mutation including the defective loci of r301 and $\mathrm{r} 304$. This indicates that the eight $r$ mutants can be classified into seven complementation groups and that at least seven cistrons are associated with fusion function in HSV2.

Table 2 shows the yields of progeny viruses from double and single infections. In many instances, the doubly infected cells produced more infectious viruses than single infections. An exception is the double infection with r301 and r303. Every pair of double infection with r304 led to yields approximately equal to the yield of the single infection with r304. The yields of the other pairs were distinctly higher than the corresponding single infections. The mechanism of the high yields in double infections is not known. The high yields indicate that some genetic interactions, including complementation, take place in doubly infected cells between mutation sites with respect to viral growth.

\section{Recombination and linkage map}

These results demonstrate that the eight $r$ mutants can be classified into seven com-
TABLE 3

Recombination between $r$ mutants of type 2 strain $N G$

\begin{tabular}{cccccccc}
\hline & r302 & r303 & r304 & r305 & r306 & r307 & r308 \\
\hline r301 & $\begin{array}{l}16.8 \\
\end{array}$ & $<0.2$ & 16.4 & 22.0 & 8.3 & 15.2 & 13.1 \\
& $(2.1)$ & & $(2.7)$ & $(2.9)$ & $(2.7)$ & $(3.0)$ & $(1.5)$ \\
r302 & & 14.5 & 17.4 & 24.0 & 22.5 & 17.2 & 13.7 \\
& & $(2.0)$ & $(3.2)$ & $(4.3)$ & $(3.0)$ & $(4.2)$ & $(3.0)$ \\
r303 & & & 0.3 & 10.5 & 7.6 & 2.5 & 4.2 \\
& & & $(0.1)$ & $(1.1)$ & $(3.2)$ & $(0.1)$ & $(1.5)$ \\
r304 & & & 14.1 & 17.4 & 3.5 & 3.4 \\
& & & & $(1.0)$ & $(1.7)$ & $(0.4)$ & $(0.5)$ \\
r305 & & & & 27.3 & 9.0 & 13.5 \\
& & & & & $(4.5)$ & $(2.3)$ & $(0.5)$ \\
r306 & & & & & 17.8 & 14.6 \\
& & & & & & $(3.4)$ & $(2.0)$ \\
r307 & & & & & & & $(2.5)$ \\
& & & & & & & \\
\hline
\end{tabular}

Values of recombination frequencies (RF) are means from three independent experiments.

Numbers in parentheses represent the standard deviations.

plementation groups and that one mutant, r303, possesses double mutation sites similar to the defective sites of r301 and r304. Recombination experiments were performed to determine the sequence of these cistrons on a genetic map. Also it was necessary to determine if the two mutations of r303 involved the same defective loci as r301 and r304.

To determine the RFs, 1,000 to 1,500 


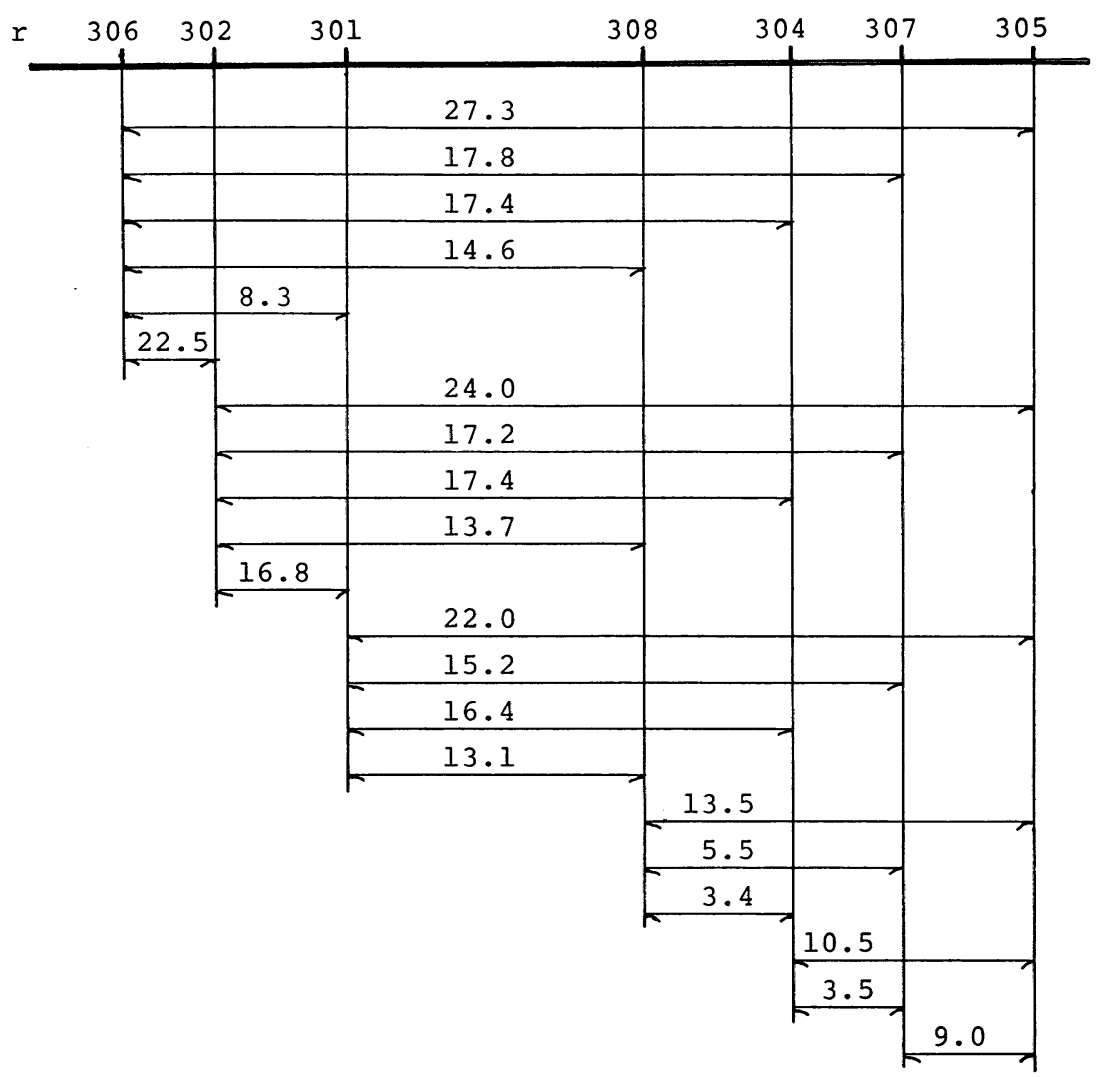

Fig. 1. Linkage map of type 2 strain NG with regard to fusion function.

The double mutant (r303) probably possesses the defects (cistron) of both $\mathrm{r} 301$ and r304, the RFs from crosses of the mutant with r301 and with r304 were $<0.2$ and 0.3 , respectively.

plaques formed by progeny viruses from each cross were checked for a syncytial or rounding phenoype. The RFs in Table 3 are the means from three independent experiments.

Seven $r$ mutants belonging to each different complementation group recombined in all possible pairs and the RFs ranged from 3.5 to 27.3 . The observations that r303 failed to recombine with $\mathrm{r} 301$ ( $\mathrm{RF}<$ 0.2 ) and recombined with $\mathrm{r} 304$ at a very low frequency $(\mathrm{RF}=0.3)$ were consistent with the results of the complementation tests.

From the data presented in Table 3, a linkage map of the mutants has been con- structed. As shown in Fig. 1, the mutations could be arranged linearly and the recombination units were nearly additive with a few exceptions involving $\mathrm{r} 302$. The exceptions were the RF (22.5) between $\mathrm{r} 302$ and $\mathrm{r} 306$, and the RF (16.8) between $\mathrm{r} 302$ and $\mathrm{r} 301$. These high values could not be reasonably explained from all the other RFs obtained.

\section{Discussion}

Syncytial mutants of HSV have been reported by a number of investigators (Hoggan and Roizman, 1959; Nii and 
Kamahora, 1961; Ejercito et al. 1968; Yamamoto et al. 1972). It has been recognized that the fusion function is genetically determined by the infecting virus and that several genes are responsible for cell fusion (Brown et al. 1973; Yamamoto and Kabuta, 1973; Yamamoto and Kabuta, 1976; Manservigi et al. 1977; Ruyechan et al. 1979; Honess et al. 1980; Little and Schaffer, 1981). On the other hand, certain viral mutants fuse in some cell types and not in others (Ruyechan et al. 1979; Palenzone et al. 1979; Haffy and Spear, 1980; Bzik and Person, 1981). This indicates that cellular factors are involved in fusion expression. To determine the gene function of the virus, it is clearly essential that the isogenic mutants and a specified cell type be used for genetic experiments.

With isogenic $r$ mutants of HSV1 and GMK cells it has been previously demonstrated that the $r$ mutants can be classified into four complementation groups and that six cistrons are probably associated with the cell fusion process (Yamamoto and Kabuta, 1977). The present work demonstrates that several genes are responsible for the expression of fusion function of HSV2 as well as HSV1. With HSV2, eight $r$ mutants were isolated and classified into seven complementation groups. The recombination experiments revealed that the seven cistrons could be arranged linearly on a linkage map. The recombination units were nearly additive, but the cause of the unreasnonably high RFs between r302 and r306 and between r302 and r301 must be investigated in more detail.

Thus $r$ mutants of HSV1 and HSV2 are now available for further genetic studies. It will be interesting to determine which cistron of HSV2 corresponds to a given cistron of HSV1, because the cistrons pertaining to cell fusion are functionally equivalent in HSV1 and HSV2 although they probably do not have the same base sequence. Unfortunately, a preliminary experiment has given no complementation bet- ween $r$ mutants of HSV1 and those of HSV2. Cleary, further studies of intertypic complementation and recombination under various conditions will be required to eluci date the structural and functional differences in the genomes of HSV1 and HSV2.

Acknowledgements: Grateful acknowledgement is made to Prof. Masahisa Shingu for his constant interest and guidance in this investigation.

\section{References}

Brown, S. M., Ritchie, D. A. and Subak-Sharpe, J.H. (1973). Genetic studies with herpes simplex virus type 1 . The isolation of temperature-sensitive mutants, their arrangement into complementation groups and recombination analysis leading to a linkage map. J. Gen. Virol. 18, 329-346.

Bzik, D. J. and Person, S. (1981). Dependence of herpes simplex virus type 1 induced cell fusion on cell type. Virology, 110, 35-42.

Ejercito, P.M., KiefF, E.D. and Roizman, B. (1968). Characterization of herpes simplex virus strains differing in their effects on social behavior of infected cells. J. Gen. Virol. 2, 357-364.

HAFFey, M.L. and Spear, P.G. (1980). Alterations in glycoprotein $\mathrm{gB}$ specified by mutants and their partial revertants in herpes simplex virus type 1 and relationship to other mutant phenotypes. J. Virol. 35, 114-128.

Hoggan, M.D. and Rolzman, B. (1959). The isolation and properties of a variant of herpes simplex producing multinucleated giant cells in monolayer cultures in the presence of antibody. Amer. H. Hyg. 70, 208-219.

Honess, R. W., Buchan, A., Halliburton, I. W. and Watson, D.H. (1980). Recombination and linkage between structural and regulatory genes of herpes simplex virus type 1: Study of the functional organization of the genome. J. Virol. 34, 716-742.

Little, S.P. and Schaffer, P.A. (1981). Expression of the syncytial (syn) phenotype in HSV-1, strain KOS: Genetic and phenotypic studies of mutants in two syn loci. Virology, $112,686-720$.

Manservigi, R., Spear, P. and Buchan, A. (1977). 
Cell fusion induced by herpes simplex virus is promoted and suppressed by different viral glycoproteins. Pro. Natl. Acad. Sci. 74, 39133917.

NiI, S. and Kamahora, J. (1961). Studies on the growth of newly isolated herpes simplex virus in vitro. Biken J. 4, 75-96.

Palenzona, A. M., Sinibaldi, P., Costanzo, F. and CASSAI, E. (1979). Influence of genetic and physiological properties of the host cell on the cytopathic expression of herpes simplex virus. Arch. Virol. 61, 127-140.

Ruyechan, W.T., Morse, L.S., Knipe, D.M. and RoIzMAN, B. (1979). Molecular genetics of herpes simplex virus: II. Mapping of the major viral glycoproteins and of the genetic loci specifying the social behavior of infected cells. J. Virol. 29, 677-697.

Suenaga, Y. (1972). Studies on the isolation and characters of type 2 herpes virus. J. Kurume Med. Assoc. 35, 1737-1747. (in Japanese)
Yamamoto, S. and Kabuta, H. (1973). Genetic studies on herpes simplex virus. I. Recombination between plaque morphology and IDU (5-iodo-2' -deoxyuridine) resistance. Kurume Med. J. 20, 87-93.

Үамамото, S. and Kabuta, H. (1976). Genetic analysis of polykaryocytosis by herpes simplex virus. II. Recombiantion between viruses with non-fusing and fusing ability. Kurume Med. J. 23, 209-217.

Yамамото, S. and Kabuta, H. (1977). Genetic analysis of polykaryocytosis by herpes simplex virus. III. Complementation and recombination between non-fusing mutants and construction of a linkage map with regard to the fusion function. Kurume Med. J. 24, 163-172.

Yamamoto, S., Kabuta, H. and Nakagawa, Y. (1972). Mutants of herpes simplex virus. I . Isolation and properties of mutants characterized by plaque size and cytopathogenicity. Kurume Med. J. 19, 23-31. 